\section{Estudo cobebate}

em Cestão Plamejamento
Revista Estudo \& Debate, Lajeado, v. 24, n. 2, 2017. ISSN 1983-036X

DOI: http://dx.doi.org/10.22410/issn.1983-036X.v24i2a2017.1324

\title{
EVASÁO FISCAL, ÉTICA E CONTROVÉRSIAS: PERCEPÇÓES DO AGENTE FISCAL SOBRE A ÉTICA FISCAL DOS CONTRIBUINTES
}

\author{
Pedro Miguel Alves Ribeiro Correia ${ }^{1}$, Isabel Cristina Gomes Maia Pires ${ }^{2}$
}

\begin{abstract}
Resumo: Com o intuito de fugir ao pagamento dos tributos, alguns contribuintes procuram meios lícitos e ilícitos, de reduzir o montante a ser recolhido, seja através da elisão fiscal, visando obter uma legítima economia de tributos, seja através da evasão fiscal, que seria o ato concomitante ou posterior à incidência tributária, onde são utilizados meios ilícitos para fugir ao pagamento. $\mathrm{O}$ fenômeno da evasão fiscal tem sido estudado há muito, porém mais recentemente também sob o prisma da moral e da ética fiscal. Alguns estudos contemporâneos apontam que a evasão fiscal pode ser considerada ética em algumas circunstâncias e antiética sob outras circunstâncias, visão que também é partilhada na literatura recente. $O$ presente estudo utilizou um instrumento de pesquisa anteriormente aplicado em vários países, e foi adaptado com o objetivo de analisar a Percepçáo da Ética Fiscal dos contribuintes na visão do Auditor Fiscal no Estado do Ceará. As conclusōes apontam para certa relatividade ética com relação à justificativa para a evasão fiscal, embora alguns argumentos apareçam com mais intensidade que outros, os resultados também demonstraram que a evasão fiscal encontra certa justificativa quando o sistema fiscal é percebido como injusto. A Corrupção governamental não encontrou justificativa ética pelos respondentes da pesquisa, em contradição com o resultado encontrado em outros inquéritos. A ampliaçáo do universo de aplicação dessa pesquisa é recomendada para alargamento da visão exploratória sobre o tema.
\end{abstract}

Palavras-chave: Evasão Fiscal. Ética Fiscal. Administração Tributária. Administração Pública.

\begin{abstract}
In order to avoid paying taxes, some taxpayers seek licit and illicit means of reducing the amount to be collected, either through tax avoidance, in order to obtain a legitimate tax savings, or through tax evasion, which would be the act Concomitant or subsequent to the tax incidence, where illicit means are used to evade payment. The phenomenon of tax evasion has been studied for a long time, but more recently also under the prism of moral and fiscal ethics. Some contemporary studies point out that tax evasion may be considered ethical in some circumstances and unethical under other circumstances, a view that is also shared in recent literature. The present study used a research instrument previously applied in several countries, and was adapted with the objective of analyzing the Perception of Fiscal Ethics of taxpayers in the view of the Fiscal Auditor in the State of Ceará. The conclusions of the study for a certain ethical relativity regarding the justification for tax evasion, although some arguments appear more intense than others, the results also showed that tax evasion finds some justification when the tax system is perceived as unfair. Government corruption did not find ethical justification by the respondents of the research, in contradiction with the result found in other inquiries. The
\end{abstract}

1 Doutoramento em Ciências Sociais (Especialidade em Administração Pública), Universidade Técnica de Lisboa (UTL). Professor no Instituto Superior de Ciências Sociais e Políticas (ISCSP), Universidade de Lisboa (Ulisboa).

2 Doutoranda em Ciências Sociais, Especialidade de Administração Pública, do Instituto de Ciências Sociais e Políticas (ISCSP), Universidade de Lisboa. 
expansion of the universe of application of this research is recommended to broaden the exploratory view on the subject.

Keywords: Tax Evasion. Tax Ethics. Tax Administration. Public Administration.

\section{INTRODUÇÃO}

A Administração Tributária Brasileira atravessa uma relevante crise sem precedentes na história do País. Dificuldades associadas à elevada carga tributária ${ }^{3}$, a complexidade da legislação, o excesso de burocracia e a corrupçáo política, dentre outros fatores, contribuem para que o nível de cumprimento fiscal seja baixo, e em contrapartida os níveis de evasão e fraude fiscal se elevem. Os resultados da Pesquisa de percepção da política fiscal brasileira, publicada pela Escola de Administração Fazendária (ESAF), em 2010, mostram que 42,6\% dos pesquisados estariam dispostos a recolher mais impostos, desde que tivessem uma maior qualidade de serviços públicos a sua disposiçâa; $53,7 \%$ não estariam dispostos a pagar mais impostos nem mesmo com o aumento da oferta de serviços públicos por parte do governo. Os resultados demonstram que o conhecimento da população brasileira sobre o tema impostos é baixa, e muitas vezes não tem consciência do que e porque paga, cerca de $22,5 \%$ dos que se declararam pagantes de impostos não souberam citar pelo menos um dos impostos que paga. Um dado curioso revela que cerca $80 \%$ da população brasileira considera a evasão fiscal um delito grave, porém está dividida quanto à probabilidade de punição, o que vem ao encontro do entendimento de Maciel (2004), de que as Legislaçóes complexas são campos propícios para evasão e elisão fiscais, à medida que tornam difíceis a açáo fiscalizadora e o cumprimento voluntário das obrigaçóes fiscais.

Cabe aqui ressaltar que uma parcela significativa da arrecadação de Receitas Tributárias no Brasil, baseia-se no sistema de self-assessment ${ }^{4}$, como também no cumprimento voluntário da legislação fiscal. Neste cenário, o montante de tributos pagos está diretamente relacionado aos níveis de cumprimento fiscal por parte dos contribuintes, e esses níveis vêm diminuindo em proporçôes consideráveis.

Ressalte-se que os tributos representam o grande suporte da ação estatal, e a fiscalidade, por sua vez, pode ser considerada um dos principais fatores de influência econômica do estado, o que leva os modernos sistemas fiscais a buscarem eficiência, eficácia e competitividade fiscal, em justaposição com os princípios clássicos de equidade, eficiência e simplicidade ao adotarem um estilo pragmático de gestâo pública. Tais mudanças explicam o aumento do interesse acadêmico pela ampliaçáo do conceito de boa governança. Hoje, a

3 O Brasil possui uma carga tributária correspondente a 33,87\% de seu Produto Interno Bruto-PIB, enquanto em países como a Argentina e México, comparáveis ao Brasil em itens como renda per capta e eficiência dos serviços públicos, a arrecadação corresponde a 15,3\% e 18,3\% de seu PIB, e em países como os Estados Unidos e Japão, nos quais serviços públicos tais como saúde e educação efetivamente funcionam, a arrecadação representa, respectivamente, 29,7\% e 21,0\% de PIB. (Souza, 2005)

$4 \mathrm{O}$ self-assessment pode ser conceituado como um mecanismo que atribui ao sujeito passivo (neste trabalho considerado Contribuinte) o dever e o direito de ser tributado conforme avaliação própria, que só pode ser alterada se houver indícios de que a lei tributária foi violada. 
boa governança é cada vez mais aplicada aos estados modernos buscando novas abordagens para a gestão pública (DE GRAFF, 2010).

Contudo, o acompanhamento do Estado Brasileiro como gestor público na fiscalidade dos tributos, ainda se configura falho. A administração Tributária Brasileira, em que pese ser considerada moderna, com a utilização dos modelos de (NPM) ${ }^{5}$ New Public Management, com foco no alcance de resultados e adoçâo de instrumentos ${ }^{6}$ de gestão privada, não contemplou a dimensão ética. Em sua relação com o contribuinte continua a assegurar a observância às normas e cumprimentos das obrigaçóes fiscais e tributárias unicamente sob a égide de fiscalizaçóes e penalidades, desconsiderando que o fenômeno da evasão fiscal está relacionado a diversos determinantes, e não somente àqueles de natureza fundamentalmente econômica apontados no modelo ${ }^{7}$ da Teoria Econômica Formal de Allingham e Sandmo (1972).

Segundo a visão de racionalidade econômica dos indivíduos, a ameaça de detecção e punição é o principal fator de influência nas decisōes sobre o cumprimento ou sobre a evasão de tributos, e envolve a avaliação da utilidade esperada em razão dos benefícios advindos de um suposto êxito na evasão fiscal e as incertezas de detençáo e punição, de modo que o pagamento de tributos ocorre em razão do receio de ser fiscalizado e punido (ALM; TORGLER, 2011; LEVINER, 2008).

Cabe aqui referir, a despeito do entendimento pacificado de que a evasão fiscal é um ato ilegítimo, criminoso, antiético e lesivo ao estado, no entanto, alguns autores (BALLAS; TSOUKAS, 1998) argumentam que a evasão fiscal pode ser ética em algumas circunstâncias e antiética sob outras circunstâncias, visão que também pode ser constatada a partir do resultado de algumas pesquisas (MCGEE; LINGLE, 2005; MCGEE, 2012a; MCGEE, 2014). Diante de tal constatação, cabe a pergunta: Qual a percepçáo da Ética Fiscal dos contribuintes na visão do Agente Fiscal?

Para responder a esta questão, o presente estudo utilizou um instrumento de pesquisa anteriormente adotado em vários países (MCGEE; LINGLE, 2005; MCGEE, 2012a; MCGEE, 2014b). Este artigo relata os resultados de um estudo empírico realizado entre os Auditores Fiscais da Receita Estadual, no Estado do Ceará, e foi conduzido com o intuito de avaliar as opiniōes dos Agentes Fiscais sobre as possíveis justificativas éticas da evasão fiscal

5 Uma das justificativas do NPM foi o de prestar mais atenção aos resultados, assumindo implicitamente um trade-off entre a governança ética e eficaz

6 Cite-se como exemplo, o Sped - Sistema Público de Escrituração Digital, instituído pelo Decreto 6.022 de janeiro de 2007, que é considerado um avanço na informatização da relaçáo entre o Fisco e os contribuintes, racionalizando e uniformizando as obrigaçôes tributárias para os contribuintes, e tornando mais efetiva a identificação de ilícitos fiscais.

7 Este modelo explica o comportamento dos contribuintes com base no risco de ser detectado e nas sançóes pecuniárias aplicadas às infraçôes. De forma subjacente, o não cumprimento das obrigaçôes fiscais ocorreria sempre que o benefício econômico associado a este comportamento fosse superior à penalização aplicada, na circunstância de o mesmo ser detectado (BRANCO DE SÁ, 2013). 
dos contribuintes. Pensar num possível valor ético para ato tâo ilegítimo é algo controverso. Esse é o parâmetro a ser considerado utilizado neste estudo.

\section{REVISÁO DA LITERATURA}

Estudar a temática fiscal em virtude da sua complexidade requer uma visão multifacetada e uma abordagem interdisciplinar do investigador (POHLMANN; LUDÍCIBUS, 2006a). Ao nos debruçarmos sobre o tema da Evasão Fiscal, encontramos autores como Andreoni e Feinstein (1998), que afirmam ser este um tema que pode ser abordado a partir de várias perspectivas: pode ser vista como um problema de finanças públicas, de coação, legal, organizacional ou ética, ou, ainda, uma combinaçáo de todos eles. O paradigma disciplinar reinante limita a análise das questóes e impede a evolução do conhecimento sobre a matéria tributária (POHLMANN; LUDÍCIBUS, 2006a).

A utilização de ferramentas econômicas para estudos sobre obediência tributária pode ser creditado a Allingham e Sandmo (1972), que aprofundaram o trabalho de Becker (1968) sobre imposição legal à análise da sonegação fiscal, usando a teoria da utilidade esperada desenvolvida por Von Neumann e Morgenstern (1944). Desde entáo, grande parte dos estudos sobre a análise econômica da sonegação, tem partido de pelo menos um exame preliminar a esse modelo teórico.

Alm et al. (2012b), argumentam que outros fatores envolvem a decisão do contribuinte, e não somente a maximização do retorno econômico, demonstrando a limitaçáo do paradigma econômico clássico, ao constatar que a probabilidade de ser auditado é mínima. Por esta via (KASTLUNGER et al., 2011), partem de uma abordagem multidisciplinar em seus estudos e acrescentam o direito, a política, a sociologia e a psicologia social.

MacGee (2012) enfatiza que embora muitos estudos tenham sido feitos sobre a conformidade fiscal, poucos têm examinado o não cumprimento, ou a evasão sob a perspectiva da ética. A maioria dos estudos sobre a evasão fiscal examina a questão através do prisma de finanças públicas ou economia, embora as questóes éticas possam ser mencionadas brevemente. Torgler (2008) discutiu a evasão fiscal sob a perspectiva das finanças públicas, mas também abordou alguns aspectos psicológicos e filosóficos da questão. McGee (2005a, 2005b, 2012b, 2014) realizou diversas pesquisas, investigando os aspectos éticos relacionados à sonegaçáo fiscal junto a contribuintes de vários países, religiōes, idades e gêneros diferentes.

$\mathrm{Na}$ área de pesquisa denominada tax morale, entendida como a predisposição intrínseca para pagar tributos, Song e Yarbrough (1978) vincularam o conceito de moral fiscal ao da ética do contribuinte, e a definiram como "as normas de conduta do cidadáo contribuinte na sua relação com o governo", enquanto os estudos de McGee e Tyler (2006) apontam para diferenças no grau de predisposiçâo entre contribuintes em função da cultura local, gênero, idade, nível de estudos, religiáo e outros dados demográficos.

O descumprimento da norma deve ser interpretado não somente como uma violação da lei, mas também como o descontentamento dos contribuintes com o que eles recebem pelos seus tributos. Por esta via, a moral fiscal relaciona-se como uma complicada interaçáo 
entre contribuintes e fisco, estabelecendo como troca justa e recíproca que envolve um dar e receber de ambas as partes (FELD; FREY, 2002).

Um importante trabalho sobre este tema, que merece ser citado, foi publicado na Espanha, onde a ética fiscal foi abordada através de distintas perspectivas: ética da administração, ética do legislador, ética do contribuinte, ética dos juízes, inclusive a ética do assessor fiscal (ALVAREZ; HERRERA, 2004). Oliva ${ }^{8}$ (1998), citado por MacGee (2006), analisou a questấo sob a perspectiva de um agente fiscal e comentou o cisma que existe entre as obrigaçóes éticas e legais de um profissional fiscal. Destaque-se que a construção da consciência fiscal coletiva não pode ser feita se os valores assinalados não estáo presentes nos agentes citados (GARCÍA; VIDAL; SERRANO, 2008).

\subsection{A Ética da Evasão Fiscal}

McGee (2014) defende três visões sobre a ética da evasão fiscal. A primeira trata a evasão fiscal como sempre, ou quase sempre, antiética. Dessa visão surgem três posiçóes adjacentes que seriam: A primeira seria a visão prevalecente em democracias, onde os cidadãos devem obedecer à maioria das regras, e, portanto têm o dever moral de pagar os tributos exigidos pelo Estado; Citando Crowe9 (1944), escreve MacGee (2014) que a segunda razão para um dever ético de pagar impostos é a crença que os indivíduos têm um dever para com os outros membros da comunidade. Esta visão sustenta uma importante oposição aos indivíduos considerados free-riding ${ }^{I 0}$, quando desfrutam dos serviços que o Estado fornece não contribuindo para o pagamento desses serviços. Um corolário desta crença é a visão de que se os sonegadores não pagam sua parte, entáo os contribuintes cumpridores da lei pagam mais do que a sua parte justa, e a terceira posição seria o dever religioso de pagar impostos;

A segunda visão da ética da evasão fiscal é abordada pelo autor, sob o ponto de vista do Anarquismo, onde o Estado não teria direito moral à cobrança de tributos, e a tributação seria considerada um roubo, considerando a inexistência de contrato social assinado entre as partes (Estado/Contribuinte) e assim, a tributaçáo seria ilegítima.

Por fim, MacGee (2014) elenca como terceira e última, a visão de que a evasão fiscal pode ser ética em algumas circunstâncias e antiética sob outras circunstâncias. Seria esta uma visão que vem se destacando, tanto na literatura (BALLAS; TSOUKAS, 1998; CROWE, 1944; MCGEE, 2012a, 2012b) como também vem sendo constatada a partir

8 Oliva, Robert R. (1998). "The Schism between Tax Practitioners' Ethical and Legal Obligations: Recommendations for the Fusion of Law and Ethics." Journal of Accounting, Ethics \& Public Policy, Volume 1, Number 4, 603-628, reprinted in Robert W. McGee (ed.), The Ethics of Tax Evasion, Dumont, NJ: The Dumont Institute for Public Policy Research: Dumont, NJ, 1998, pp. 350-371.

9 Martin Timothy Crowe é autor de um dos mais respeitados trabalhos sobre ética e evasão fiscal, que foi a sua tese de doutorado escrita 1944, intitulado "The Moral Obligation of Paying Just Taxes".

10 O free-riding ou "andar à boleia" traduz a situação em que um indivíduo usufrui de um bem ou serviço, que não ajudou a custear. 
dos resultados de alguns inquéritos aplicados em diversos países (MCGEE; LINGLE, 2005; MCGEE, 2012A; MCGEE, 2014).

\subsection{Evasão Fiscal: Determinantes Econômicos e Determinantes Sociais}

Para escapar ao pagamento dos tributos, pelos mais diversos fatores, alguns contribuintes buscam caminhos e desvios alternativos lícitos e ilícitos, seja através da elisão fiscal, visando obter uma legítima economia de tributos, fugindo ao alcance da norma tributária, impedindo a ocorrência do fato gerador, ou reduzindo o montante de tributos a recolher; seja através da evasão fiscal, que seria o ato concomitante ou posterior à incidência tributária, onde são utilizados meios ilícitos como a sonegação, a simulação, ou a fraude. Como bem observa Torgler (2008), a evasão fiscal é um problema recorrente em vários países, diminuindo a arrecadação e consequentemente levando as administrações tributárias a gastarem somas vultosas de recursos para coibir a fraude fiscal.

Na visão de Huck (1997), evasão e elisão fiscal são fenômenos sociais que coexistem com a figura do imposto, não importando o grau de desenvolvimento econômico ou cultural do povo, pois o objetivo de sempre pagar menos impostos é uma constante na sociedade, enquanto a elisão fiscal seria "o retardamento, a redução ou a descaracterização do fato gerador que dá origem ao pagamento de um tributo, sem, contudo violar a lei” é a faculdade do indivíduo em estruturar seu negócio jurídico de forma lícita, através dos meios disponíveis no direito privado, de modo a não constituir o fato gerador, abortando o nascimento da obrigação tributária. É o planejamento tributário (HUCK, 1997).

Existe uma linha divisória muito tênue de diferenciação entre a elisão e a evasão fiscal, considerando o impacto semelhante que causam no sistema tributário do país. Embora sejam termos distintos, ambas guardam em comum a característica de serem técnicas de não-submissão à norma tributária. Partindo do conceito constante no glossário tributário internacional do International Bureau of Fiscal Documentation - IBFD ${ }^{11}$, temos que:

\footnotetext{
Elisão fiscal. Este termo é utilizado para denotar a redução dos encargos tributários por meios legais. Frequentemente é usado em sentido pejorativo, como quando é utilizado para descrever a economia de impostos atingida através de arranjos artificiais dos negócios pessoais ou empresariais, aproveitando- se da existência de lacunas, anomalias ou outras deficiências no direito tributário. (...). Em contraste com a elisão, a evasão fiscal é a redução de impostos obtida por meios ilícitos.

Evasão Fiscal. Este termo é aplicado para a economia de impostos atingida por meios ilegais, incluindo-se nestes a omissão da renda tributável ou de transaçôes realizadas das declaraçôes de tributos, ou a reduçáo da quantia devida por meios fraudulentos. (IBDF, 2005. p. 22; 101) [grifamos]
}

MacGee (2012) observa que a grande maioria dos artigos escritos sobre evasão fiscal foi escritos sob a perspectiva das finanças públicas, onde se discutem aspectos técnicos da evasão fiscal e os efeitos primários e secundários que esta produz sobre uma economia.

11 IBDF - International Bureau of Fiscal Documentation (2005). International Tax Glossary. 5th Ed. The Netherlands, Barry Larking, 
Em alguns casos, há também uma discussão sobre como prevenir ou minimizar a evasão fiscal. Cabe aqui ressaltar que, na linha de estudos relacionados à evasão fiscal, alguns autores têm se dedicado a estudar a predisposiçáo intrínseca para o pagamento de tributos, e apontam diferenças em tal predisposição em função tanto de características pessoais do indivíduo, como também relacionadas ao ambiente em que ocorre a tributação e retorno social dos tributos (MCGEE , 2005a, 2005b, 2012, 2014b; MCGEE; LINGLE, 2005; HERNANDEZ; MCGEE, 2014A).

Num recente estudo realizado em três Países latino-americanos ${ }^{12}$, MacGee (2014) relata que apesar de os brasileiros se oporem fortemente à evasão fiscal, essa oposição é relativa em alguns casos. Autores como Torgler (2008) e Molero e Pujol (2005) apontam que, entre as variáveis não econômicas, a moralidade fiscal tem um papel importante na explicaçấo das taxas de cumprimento e também nas taxas de evasão fiscal. Esta característica ajuda a explicar o alto nível de cumprimento fiscal e tem um forte impacto na economia não registrada e na evasão fiscal (TORGLER; SCHNEIDER, 2007).

\subsection{Da Ética Fiscal}

A noção de ética fiscal implica em condutas dos contribuintes, que devem respeitar os valores subjetivos e objetivos da sociedade, dentre eles o pagamento do tributo, implicando também na conduta do Estado, que não pode observar somente os aspectos formais da tributação, mas todos os valores éticos que contribuam para um sistema justo conforme o Direito (KLEIN, 2012). A ética fiscal, ao menos conforme admite o senso comum, vinculase à concepçáo e à prática de regras justas em matéria tributária. Aponta para questôes, não raro conflitantes, que envolvem as limitaçōes do poder de tributar, os direitos dos contribuintes, o dever fundamental de pagar impostos, o equilíbrio concorrencial, a prevençáo das guerras fiscais, etc (MACIEL ,2004).

Klaus Tipke (2002, p. 21) afirma que há várias éticas, destacando-se a ética do legislador, a ética fiscal da Administração Tributária e a ética do contribuinte, e define a ética fiscal como "a teoria que estuda a moralidade das açóes em matéria fiscal desenvolvidos pelos poderes públicos - legislativo, executivo e judiciário - e pelos cidadãos contribuintes". $\mathrm{O}$ autor observa que, a ética fiscal, apesar de ser um tema recorrente nos debates fiscais, apresenta deficiências que são justamente um reflexo da deficiente moral fiscal do Estado, posto que uma situaçáo seja consequência da outra. Neste sentido, a moral fiscal relacionase como uma complicada interação entre contribuintes e fisco, estabelecendo como troca justa e recíproca que envolve um dar e receber de ambas as partes (FELD; FREY, 2002).

Maciel (2004) não encontra horizonte visível para a estabilidade de padrôes éticos no campo tributário brasileiro, posto que essa meta demanda uma ampla reestruturação de relacionamentos entre os fiscos e os contribuintes. Nas palavras de Quaresma (2008) "[...] a ética, quando aplicada no terreno tributário, inclui os procedimentos de quaisquer servidores fazendários, como também do legislador, do julgador, do procurador, do contribuinte pagador de tributos, do gerente e planejador fiscal, do aplicador dos recursos

12 Argentina, Brasil e Colômbia. 
tributários. Cada qual, dentro das vinculadas obrigaçóes, precisa desincumbir-se das suas funçóes conforme a ética e as normas morais e jurídico-tributárias” (p. 89-90).

A ética fiscal, como conjunto de valores que guiam o atuar, onde se destacam a justiça, a igualdade e a solidariedade, é o que fundamenta a consciência fiscal, e para que os cidadãos possam visualizar os princípios nos quais está baseada, a ética precisa se sobressair com contundência sobre a força que sustenta a coerção (GARCIA; VIDAL, 2004). Essa força de coerção a que os autores se referem, é emblemática quando se refere a uma relação mais próxima entre o fisco e o cidadão, ou, em outras palavras, entre o Agente Fiscal executor e o contribuinte. Encerra, portanto, na visão de Maciel (2004) questóes concernentes às relaçóes entre o fisco e o contribuinte, entre os contribuintes e entre os fiscos, e a motivação intrínseca ao cumprimento fiscal ou ao seu descumprimento, onde a evasão fiscal se enquadra, é uma dessas questóes.

É, portanto, nesse diapasão de relaçóes comportamentais que se insere o presente trabalho, elegendo-se a ética fiscal dos contribuintes como primado a ser entendido pelos agentes fiscais na sua atuação em seu mister estatal. Baseados nessa premissa, um dos grupos que nos interessou estudar com maior amplitude foi o dos Auditores Fiscais, posto que, teoricamente seja um grupo diferenciado, em relação aos componentes éticos que fundamentam a consciência fiscal. Na secção seguinte procedemos à análise da metodologia utilizada.

\section{METODOLOGIA}

Considerando que os contribuintes apresentam comportamentos diferentes perante as suas obrigaçóes fiscais (KASTLUNGER et al., 2011), é possível conjeturar que a percepção que o agente fiscal possa ter com relação ao comportamento do contribuinte no que se refere à justificação ética para a evasão fiscal, pode ser um ponto de partida para entender este fenômeno e suas variantes, uma vez que, nessa relação mais próxima, emergem particularidades motivadas pelas condutas e componente éticos de ambos os atores, que, acreditamos, precisam ser conhecidas. A importância do presente estudo reside no caráter inovador e pioneirismo em avaliar a ética fiscal do contribuinte na perspectiva do agente fiscal com a realização de um inquérito.

O universo da pesquisa se constituiu de Auditores Fiscais da Secretaria da Fazenda do Estado do Ceará - SEFAZ-CE, que desempenham atividades de Fiscalização de Empresas. Ressalte-se que o critério de seleção dessa população, justifica-se em função da especificidade da função de auditoria fiscal, onde, via de regra, ocorre um contato pessoal do Agente Fiscal executor com o contribuinte descumpridor. Foram aplicados 251 questionários, e destes, um total de 164 respostas utilizáveis foram obtidas. A taxa de resposta foi de 65,33\%.

O questionário consistiu de 14 afirmaçôes, onde foram descritas situaçóes sobre evasão fiscal de impostos, que na visão do contribuinte: "Seriam éticas". Solicitou-se que o respondente, na qualidade de Agente Fiscal, interpretasse as afirmaçóes a partir de sua percepção sobre a ética fiscal dos contribuintes. Usando uma escala de Likert de sete pontos, os respondentes foram solicitados a escolher o item apropriado no espaço fornecido, para indicar a extensão de seu acordo ou desacordo com cada afirmação. 
A amostra realizada seguiu o critério de conveniência. Essa pesquisa obedeceu ao método quantitativo, que de acordo com Marconi e Lakatos (2011), que citam Richardson et al. (1999, p. 70), "[...] caracteriza-se pelo emprego da quantificaçáo tanto nas modalidades de coleta de informaçōes quanto no tratamento delas por meio de técnicas estatísticas".

As hipóteses são consideradas fatores determinantes no processo de desenvolvimento da pesquisa. Para Gil (2008), as hipóteses são proposições que serão testadas, e que podem vir a ser a solução do problema. Com base na revisão de Literatura e nos resultados das pesquisas já anteriormente aplicadas, foram construídas quatro hipóteses:

H1: O entrevistado médio acreditará que, para o contribuinte, a evasão fiscal é ética às vezes.

H2: O Agente Fiscal acredita que, para o contribuinte, a evasão fiscal será mais justificada (as pontuaçôes serão mais baixas) quando a afirmação se refere à corrupção governamental.

H3: O entrevistado acreditará que para o contribuinte, a evasão fiscal será menos justificada (a pontuação será maior), quando ele percebe que está recebendo benefícios em troca do imposto pago (Afirmação 9), onde os fundos estão sendo gastos corretamente (Afirmação7), ou, onde há uma percepçáo de que existe um dever para com outros contribuintes de pagar impostos (Afirmação 14), mesmo que não haja um dever para com o governo.

H4: O Agente Fiscal acredita que, para o contribuinte, a evasão fiscal será mais justificável (a pontuação será menor) quando o sistema fiscal é percebido como sendo injusto.

\subsection{Modelo de Análise}

De forma a responder à questâo de partida, quatro hipóteses foram definidas e escolhidas para serem testadas, a elaboração do modelo de análise e sua forma de operacionalizaçáo, teve por base o padrão utilizado anteriormente por McGee (2012a), e nele estão presentes os principais conceitos-chave deste estudo.

Quadro1 - Hipóteses de investigação

\begin{tabular}{|l|l|}
\hline Hipóteses & Operacionalização \\
\hline $\begin{array}{l}\text { H1: O entrevistado médio acreditará que, para o } \\
\text { contribuinte, a evasão fiscal é ética às vezes. }\end{array}$ & $\begin{array}{l}\text { Esta hipótese não será rejeitada se a pontuação } \\
\text { média para todas as 14 afirmaçóes for superior a } \\
\text { 2, mas inferior a 6. }\end{array}$ \\
\hline $\begin{array}{l}\text { H2: O Agente Fiscal acredita que, para o o } \\
\text { contribuinte, a evasão fiscal será mais aceitável } \\
\begin{array}{l}\text { (as pontuaçóes serão mais baixas) quando a a } \\
\text { afirmação se refere à corrupçáo governamental. }\end{array}\end{array}$ & $\begin{array}{l}\text { Esta hipótese não será rejeitada se a afirmação } \\
\text { que trata da corrupção (Questão 11) for } \\
\text { classificada dentro do item 6. }\end{array}$ \\
\hline
\end{tabular}




\begin{tabular}{|c|c|}
\hline Hipóteses & Operacionalizaçáo \\
\hline $\begin{array}{l}\text { H3: O entrevistado acreditará que para } \\
\text { o contribuinte, a evasão fiscal será menos } \\
\text { justificada (a pontuação será maior), quando ele } \\
\text { percebe que está recebendo benefícios em troca } \\
\text { do imposto pago (Afirmação 9), onde os fundos } \\
\text { estáo sendo gastos corretamente (Afirmaçáo7), } \\
\text { ou, onde há uma percepção de que existe um } \\
\text { dever para com outros contribuintes de pagar } \\
\text { impostos (Afirmaçáo 14), mesmo que não haja } \\
\text { um dever para com o governo. }\end{array}$ & $\begin{array}{l}\text { Esta hipótese não será rejeitada se as afirmações } \\
\text { que solicitam opinióes sobre esses pontos } \\
\text { estiverem entre as } 7 \text { pontuaçóes mais altas. }\end{array}$ \\
\hline $\begin{array}{l}\text { H4: O Agente Fiscal acredita que, para o } \\
\text { contribuinte, a evasão fiscal será mais justificável } \\
\text { (a pontuaçáo será menor) quando o sistema } \\
\text { fiscal é percebido como sendo injusto. }\end{array}$ & $\begin{array}{l}\text { Esta hipótese não será rejeitada se as pontuações } \\
\text { para as afirmaçóes } 1,3 \text { e } 14 \text { estiverem todas } \\
\text { dentro das sete melhores pontuaçóes. }\end{array}$ \\
\hline
\end{tabular}

Fonte: Elaborado pelos autores, com base no trabalho de MacGee (2005, 2006, 2009)

\section{ANÁLISES E DISCUSSÓES}

No que se refere à análise dos dados coletados no inquérito e considerando o referencial teórico, e as hipóteses formuladas, importa sublinhar o que segue:

\subsection{Das Hipóteses}

H1: O entrevistado médio acreditará que, para o contribuinte, a evasão fiscal é ética às vezes. Esta hipótese seria confirmada se a pontuação média para todas as 14 afirmaçôes recebesse pontuação superior a 2 , mas inferior a 6 .

H1: Confirmada. A pontuação média foi de 4, 560. Esta constataçấo é consistente com o resultado das pesquisas ${ }^{13}$ já realizadas em outros países, e também com a investigação realizada mais recentemente por MacGee (2014) e que serviram de esteio para a consecução deste estudo. Percebe-se que basicamente, existe pouco apoio moral dos respondentes para a evasáo fiscal, embora alguns argumentos sejam mais fortes do que outros, o que aponta para certa relatividade ética com relação à justificativa para a evasão fiscal.

H2: O Agente Fiscal acredita que, para o contribuinte, a evasão fiscal será mais justificada (as pontuaçôes serão mais baixas) quando a afirmação se refere à corrupção governamental. Esta hipótese seria confirmada se a afirmação que trata da corrupçáo (Questão 11) fosse classificada dentro do item 6.

H2: Rejeitada. A afirmação recebeu a pontuação de 5, 7012. A questão que trata da corrupção ficou em décimo lugar, o que é um resultado surpreendente, e contradiz o resultado encontrado em estudos anteriores (McGee e Lingle, 2005; Hernandez e McGee, 2014a). Uma possível explicação para este resultado é que na visão de um expressivo

13 McGee (2006), McGee e Tyler (2006) ; McGeee López Palau (2007). 
número de Agentes Fiscais entrevistados, em sua relação com o contribuinte incumpridor, prepondera o paradigma do Homo Economicus, guiado somente pelo interesse econômico próprio, e, portanto, é racional e amoral, disposto a maximizar seus benefícios financeiros a qualquer custo. Ressalte-se que os modelos econômicos tradicionais ignoram a motivação intrínseca dos indivíduos ao cumprimento das suas obrigações fiscais. A decorrência lógica desse raciocínio pode ser constatada quando a Administração Tributária assegura a observância fiscal, com o aumento de fiscalizações ou a severidade nas punições, ou com o uso das duas ferramentas de modo concomitante, o que Alm e Torgler (2011) nomearam de "insight plausível".

H3: O entrevistado acreditará que para o contribuinte, a evasão fiscal será menos justificada (a pontuação será maior), quando ele percebe que está recebendo benefícios em troca do imposto pago (Afirmação 9), onde os fundos estão sendo gastos corretamente (Afirmação7), ou, onde há uma percepção de que existe um dever para com outros contribuintes de pagar impostos (Afirmação 14), mesmo que não haja um dever para com o governo. Esta hipótese se confirmaria se as declaraçóes que solicitavam opinióes sobre esses pontos estivessem entre as 7 pontuaçóes mais altas.

H3: Rejeitada. Das (3) três afirmaçôes, somente uma (1) foi classificada. Das três afirmaçóes selecionadas, somente a 7 (onde os fundos estão sendo gastos corretamente) foi classificada entre as sete maiores pontuaçóes. A rejeição desta hipótese sinaliza certa tolerância (ou justificativa ética) para a evasão fiscal do contribuinte. Neste contexto, o Agente Fiscal interpreta que quando os contribuintes reconhecem que os valores dos tributos são utilizados para o bem comum e compreendem a necessidade de financiamento da atividade pública, o cumprimento fiscal ocorre como uma atitude natural (Alm et al. , 2012b). Fatores relacionados à má gestão dos recursos arrecadados, e uma baixa contrapartida dos serviços públicos oferecidos pelo estado, aparecem com certa tolerância (ou justificativa ética) para a evasão fiscal, resultado que vem ao encontro da pesquisa realizada pela ESAF, já mencionada, onde $42,6 \%$ dos entrevistados mostraram-se dispostos a recolher mais impostos, desde que houvesse uma contrapartida do Estado com relação à qualidade dos serviços públicos disponibilizados.

A baixa pontuação percebida na Afirmação 14 (Onde há uma percepção de que existe um dever para com outros contribuintes de pagar impostos), contraria os argumentos relacionados por MacGee (2014) no que diz respeito é a crença de que os indivíduos têm um dever ético para com os outros membros da comunidade. Com relação à baixa pontuação da Afirmação 9 (Quando ele percebe que está recebendo benefícios em troca do imposto pago), o resultado pode ser de algum modo, compreendido pelo fato de que os próprios entrevistados (os Agentes Fiscais) concordarem com o pressuposto de que o dinheiro arrecadado pelo Estado é mal aplicado, indicando um mau desempenho da sua atividade. Neste sentido, o descumprimento da norma fiscal passa a ser interpretado não somente como uma violação da lei, mas também como o descontentamento dos contribuintes com o que eles recebem pelos seus tributos (FELD; FREY, 2002).

H4: O Agente Fiscal acredita que, para o contribuinte, a evasão fiscal será mais justificável (a pontuação será menor) quando o sistema fiscal é percebido como sendo 
injusto. Esta hipótese seria confirmada se as pontuaçóes para as questóes 1, 3 estivessem ambas dentro das sete melhores pontuaçóes.

H4: Confirmada. As questóes 1 e 3 ficaram entre as sete melhores pontuações. As duas declaraçôes "A evasão Fiscal é ética, porque o Sistema Tributário é injusto" $(6,1402)$ e "A evasão fiscal é ética, se as alíquotas de impostos forem muito elevadas" (5,7683), receberam as maiores pontuaçóes, e se classificaram em $11^{\circ}$ e $13^{\circ}$ lugares, revelando portanto, um alto nível de concordância dos inquiridos.

É provavelmente o resultado que menos surpreende no resultado final da pesquisa, confirmando estudos anteriores, onde se concluíram que a oposição à evasão fiscal é mais fraca nos casos em o sistema Tributário é percebido como sendo injusto. Seguindo a linha de raciocínio de Kirchler (2007) ao afirmar que o cumprimento fiscal voluntário é influenciado pela percepção de justiça e das normas sociais, o que, por sua vez, robustece a cooperação e a observância voluntária, tal resultado permite concluir que na percepção do Agente Fiscal a ética fiscal do contribuinte guarda estreita relação com a percepção externa das administrações tributárias.

A Tabela 1 (Média Amostral de Afirmativas de Avaliação) lista as 14 afirmaçóes avaliadas e os escores médios recebidos para cada afirmação.

- Uma pontuação de um (1) indica forte concordância com a afirmação. Uma pontuação Sete (7) indica forte desacordo.

- Uma pontuação média ou, 2 ou menos indicaria que a evasão fiscal é sempre, ou quase sempre ética. Uma pontuação média de 6 ou mais indicaria que a evasão fiscal nunca é ou quase nunca ética. Pontuações com média de mais de 2 , mas menos de 6 , indicam que a evasão fiscal às vezes é ética.

Tabela 1 - Média amostral dos valores éticos diante da evasão fiscal

\begin{tabular}{|c|c|c|}
\hline QUESTÃO & AFIRMATIVA DE AVALIAÇÃO - ÉTICA DA EVASÃO FISCAL & MÉDIA \\
\hline 1 & A evasão fiscal é ética, se as alíquotas de impostos forem muito elevadas & 5,7683 \\
\hline 2 & $\begin{array}{l}\text { A evasão fiscal é ética mesmo que as alíquotas de imposto sejam baixas, } \\
\text { porque o governo não tem direito de tirar tanto dinheiro do cidadão }\end{array}$ & 2,9329 \\
\hline 3 & A evasão Fiscal é ética, porque o Sistema Tributário é injusto & 6,1402 \\
\hline 4 & $\begin{array}{l}\text { A evasão fiscal é ética, se grande parte do dinheiro arrecadado é } \\
\text { desperdiçada. }\end{array}$ & 6,1280 \\
\hline 5 & $\begin{array}{l}\text { A evasão fiscal é ética, mesmo que parte do dinheiro arrecadado seja } \\
\text { gasto corretamente }\end{array}$ & 2,7927 \\
\hline 6 & $\begin{array}{l}\text { A evasão fiscal é ética, se uma grande parte do dinheiro arrecadado é } \\
\text { gasto em projetos que ele desaprova moralmente. }\end{array}$ & 4, 0305 \\
\hline 7 & $\begin{array}{l}\text { A evasão fiscal é ética, mesmo quando uma grande parte do dinheiro } \\
\text { arrecadado é gasto em projetos que valem a pena }\end{array}$ & 5,4451 \\
\hline 8 & $\begin{array}{l}\text { A evasão fiscal é ética ,se grande parte do dinheiro arrecadado é gasto em } \\
\text { projetos que não lhe beneficiam }\end{array}$ & 6,1463 \\
\hline 9 & $\begin{array}{l}\text { A evasão fiscal é ética mesmo quando grande parte do dinheiro } \\
\text { arrecadado é gasto em projetos que lhe beneficiam. }\end{array}$ & 5,0732 \\
\hline
\end{tabular}




\begin{tabular}{|c|c|c|}
\hline QUESTÁO & AFIRMATIVA DE AVALIAÇÃO - ÉTICA DA EVASÃO FISCAL & MÉDIA \\
\hline 10 & A evasão fiscal é ética se todos estiverem fazendo & 5,1829 \\
\hline 11 & $\begin{array}{l}\text { A evasão fiscal é ética, se uma parte significativa do dinheiro arrecadado } \\
\text { é desviado para a corrupçáo }\end{array}$ & 5,7012 \\
\hline 12 & A evasão fiscal é ética, se a probabilidade do fisco detectar for baixa. & 3,1646 \\
\hline 13 & A evasão fiscal é ética, se eu não tenho condiçôes de pagar & 2, 4939 \\
\hline 14 & $\begin{array}{l}\text { A evasão fiscal é ética, mesmo que, se ele pagar menos, outros tenham } \\
\text { que pagar mais. }\end{array}$ & 2,8415 \\
\hline
\end{tabular}

Fonte: Elaborada pelos autores, com base nos trabalhos de MacGee (2005, 2006, 2009)

A Tabela 2 classifica todos os argumentos ou afirmativas de análise utilizadas no inquérito, da mais aceitável para a menos aceitável. Das 14 pontuaçóes totais, somente 3 ficaram acima de 6,00, e nenhuma apresentou escores de 2,0 ou menos. Os escores variaram de 2, 4939 a 6, 1463, indicando que alguns argumentos foram mais fortes do que outros.

Tabela 2 - Classificação das Afirmativas de Avaliação sobre Ética e Evasão Fiscal

\begin{tabular}{|c|c|c|}
\hline QUESTÁO & AFIRMATIVA DE AVALIAÇÁO & RANKING \\
\hline 13 & A evasão fiscal é ética, se eu não tenho condiçôes de pagar & 2,4939 \\
\hline 5 & $\begin{array}{l}\text { A evasão fiscal é ética, mesmo que parte do dinheiro arrecadado seja } \\
\text { gasto corretamente }\end{array}$ & 2,7927 \\
\hline 14 & $\begin{array}{l}\text { A evasão fiscal é ética, mesmo que, se ele pagar menos, outros tenham } \\
\text { que pagar mais. }\end{array}$ & 2,8415 \\
\hline 2 & $\begin{array}{l}\text { A evasão fiscal é ética mesmo que as alíquotas de imposto sejam } \\
\text { baixas, porque o governo não tem direito de tirar tanto dinheiro do } \\
\text { cidadáo }\end{array}$ & 2,9329 \\
\hline 12 & A evasão fiscal é ética, se a probabilidade do fisco detectar for baixa. & 3,1646 \\
\hline 6 & $\begin{array}{l}\text { A evasão fiscal é ética, se uma grande parte do dinheiro arrecadado é } \\
\text { gasto em projetos que ele desaprova moralmente. }\end{array}$ & 4,0305 \\
\hline 9 & $\begin{array}{l}\text { A evasão fiscal é ética mesmo quando grande parte do dinheiro } \\
\text { arrecadado é gasto em projetos que lhe beneficiam. }\end{array}$ & 5,0732 \\
\hline 10 & A evasão fiscal é ética se todos estiverem fazendo & 5,1829 \\
\hline 7 & $\begin{array}{l}\text { A evasão fiscal é ética, mesmo quando uma grande parte do dinheiro } \\
\text { arrecadado é gasto em projetos que valem a pena }\end{array}$ & 5,4451 \\
\hline 11 & $\begin{array}{l}\text { A evasão fiscal é ética, se uma parte significativa do dinheiro } \\
\text { arrecadado é desviado para a corrupção }\end{array}$ & 5,7012 \\
\hline 1 & $\begin{array}{l}\text { A evasão fiscal é ética, se as alíquotas de impostos forem muito } \\
\text { elevadas }\end{array}$ & 5,7683 \\
\hline 4 & $\begin{array}{l}\text { A evasão fiscal é ética, se grande parte do dinheiro arrecadado é } \\
\text { desperdiçada. }\end{array}$ & 6,1280 \\
\hline 3 & A evasão Fiscal é ética, porque o Sistema Tributário é injusto & 6,1402 \\
\hline 8 & $\begin{array}{l}\text { A evasão fiscal é ética, se grande parte do dinheiro arrecadado é gasto } \\
\text { em projetos que não lhe beneficiam }\end{array}$ & 6,1463 \\
\hline
\end{tabular}

Fonte: Elaborada pelos autores, com base nos trabalhos de MacGee (2005, 2006, 2009). 
Como visto na Tabela 1, os escores médios estavam acima de 2,0 e abaixo de 6,0, indicando que na visão do Agente Fiscal, o contribuinte considera que a evasão fiscal se justifica em algumas circunstancias, em outras palavras, para o contribuinte a evasão fiscal às vezes é ética.

\subsection{Particularidades da Menor e Maior Pontuação}

Um resultado bastante peculiar pode ser observado nos resultados obtidos com relação à afirmação (13): "A evasão fiscal é ética, se eu não tenho condições de pagar”, que ao final da avaliação aparece com a menor pontuação $(2,4939)$ de todo o inquérito, indicando que para uma maioria significativa de agentes fiscais, este é o argumento que mais justifica a evasão fiscal na percepção do contribuinte. Tal resultado pode ser analisado considerandose que na visão do Agente Fiscal, a carga tributária imposta é abusiva e viola o Princípio da Capacidade Contributiva de alguns contribuintes, ou outra possível interpretação para este resultado pode residir no entendimento corrente da chamada "sonegação de sobrevivência", uma espécie de necessidade para defesa da vida de muitos contribuintes, ressalte-se que num país de subdesenvolvido, submetido a altas taxaçóes, este é um fenômeno que já se observava de forma empírica, e que a aplicação do inquérito nos possibilita confirmar.

Como se pode observar, a afirmação "A evasão fiscal é ética, se grande parte do dinheiro arrecadado é gasto em projetos que não lhe beneficiam", recebeu a maior pontuação (a oposição do respondente à justificativa de evasão fiscal foi mais forte). Contrariando, de certo modo, os resultados e as conclusóes obtidas nas pesquisas anteriormente realizadas por MacGee et all $^{14}$., nas quais se baseou este estudo. Uma possível interpretação para a alta pontuação desta afirmação $(6,1463)$ pode ser atribuída ao fato de os Agentes Fiscais, ao responderem ao inquérito, estarem aplicando as suas próprias regras morais, sem levar em consideração as possíveis exceçôes. Outra possível explicação seria a de que os entrevistados acreditam na obrigação de sempre pagar impostos, provavelmente em função da natureza positivista do próprio cargo que ocupam.

\section{CONCLUSÓES}

A rigor e dentro do entendimento social pacificado, a aceitação da evasão fiscal seria a definição negativa de ética fiscal, ou ainda, este tipo de tolerância seria a expressão mais emblemática de uma sociedade com baixa consciência fiscal. Contudo, ao final do presente estudo realizado, as conclusóes apontam que a evasão fiscal pode ter justificaçóes éticas. Às vezes.

A análise dos dados levantados aponta para certa relatividade ética com relação à justificativa para a evasão fiscal, embora alguns argumentos apareçam com mais intensidade que outros. Um desses argumentos revelou que a evasão fiscal será mais justificável quando o sistema fiscal for percebido como sendo injusto. Fatores relacionados à má gestão dos recursos arrecadados, e uma baixa contrapartida dos serviços públicos oferecidos pelo

14 McGee, 2005a \& b McGee \& Lingle, 2005. 
estado, também aparecem com uma certa tolerância (ou justificativa ética) para a evasão fiscal. A Corrupção governamental não encontrou justificativa ética pelos respondentes deste estudo, em contradiçáo com o resultado encontrado em outros inquéritos. De certo modo, a relatividade ética considera que as situaçôes interferem na concepção dos valores e da conduta socialmente aceitável.

Importa salientar que decidimos não utilizar afirmaçóes relacionadas a direitos humanos, como imposição de convicçóes políticas por parte do governo à populaçáo, discriminação por características pessoais e o fato de ser judeu em meio à Alemanha Nazista, que constavam no inquérito original no qual se baseou este estudo. Para o autor do inquérito, se a evasão fiscal fosse sempre justificada, seria justificada neste caso. Argumentar de outra forma seria afirmar que, a rigor, os judeus teriam a obrigação ética de pagar impostos aos nazistas para pagar o gás venenoso usado para matar os contribuintes e suas famílias. No referido questionário, a afirmativa "A evasão fiscal seria ética se eu fosse um judeu que vive na Alemanha nazista - segundo o autor, foi incluído para testar os limites de tolerância à evasão fiscal. No entanto, optamos pela exclusão das referidas afirmaçóes, sem prejuízo do resultado final do inquérito.

De forma geral, os resultados e conclusóes obtidas nas pesquisas sobre Ética Fiscal são de considerável importância. A percepção da ética fiscal dos contribuintes na visão da autoridade fiscal parece ser um dos fatores determinantes na melhoria do cumprimento fiscal e consequente diminuição das taxas de evasão fiscal. Considerando-se que no Brasil, não temos encontrado um debate teórico importante sobre a evasão fiscal sob a perspectiva da ética fiscal dos contribuintes, mais estudos empíricos são necessários para melhor aprofundamento sobre a ética fiscal do contribuinte na perspectiva do Agente Fiscal.

Uma limitaçáo importante do estudo se refere ao tamanho da amostra, que ao se apresentar circunscrito aos Agentes Fiscais de uma Região, somente permite considerar os resultados encontrados para a populaçáo em questáo. Considerando que, assim como os contribuintes, os agentes fiscais também apresentam diferenças relacionadas ao ambiente em que ocorre a evasão fiscal, e também considerando a influência da Cultura Fiscal em cada regiáo, sugere-se a replicaçáo ou a ampliação do universo de aplicaçấo desse estudo, abrangendo Agentes Fiscais de outros estados da federação Brasileira.

\section{REREFÊNCIAS}

ALM, J; TORGLER, B. Culture differences and tax morale in the United States and in Europe. CREMA Working Paper No. 2004-14, 2003. Disponível em < SSRN: http:// ssrn.com/abstract=562861 > Acesso em Dez. de 2016.

ALM, J.; TORGLER, B. Do ethics matter? Tax compliance and morality. Journal of Business Ethics, v. 101, p. 635-651, 2011

ALM, J.; KIRCHLER, E.; MÜEHLBACHER, S.; GANGL, K.; HOFMANN, E.; KOGLER, C.; POLLAI, M. Rethinking the research paradigms for analyzing tax compliance behavior. CESifo Forum, v. 13, n. 2, p. 33-40. 2012 b. 
ANDREONI, J. B. E.; FEINSTEIN, J. Tax Compliance. Journal of Economic Literature, v. 36, n. 2, p. 818-860, 1998.

BECKER, G. Crime and punishment: an economic approach. Journal of Political Economy, v. 76, p. 169-217, 1968.

BRANCO DE SÁ, C. I. Fatores determinantes da moral tributária em Portugal: Uma análise através da aplicação de um modelo de equações estruturais. 2013. Dissertação de Doutoramento em Gestão de Empresas, Faculdade de Economia da Universidade de Coimbra.

CROWE, M. T. The Moral Obligation of Paying Just Taxes. The Catholic University of America Studies in Sacred Theology, n. 84, 1944.

DE GRAAF, G.; VAN DER WAL, Z. Managing conflicting public values: Governing with integrity and effectiveness. The American Review of Public Administration, v. 40, n.6, p. 623-630, 2010.

FELD, L. P.; FREY, B. S. Trust breeds trust: How taxpayers are treated. Economics of Governance, v. 3, n. 2, p. 87-99, 2002.

FELD, L. P.; FREY, B. S. Tax Compliance as the Result of a Psychological Tax Contract: The Role of Incentives and Responsive Regulation. Law \& Policy, v. 29, n. 1, p. 102-120, 2007.

GARCÍA, G. A., VIDAL, E. Q. The mediation and transaction: the tax conscience, comunicación presentada al y recogida en las actas del 28th International Congress of Psychology (ICP2004), August 8 to August 13, Beijing, China. 2004.

GARCÍA, G. A.; VIDAL, E. Q.; SERRANO, A. M. La Conciencia Fiscal en España, Rivista Diritto e Pratica Tributaria Internazionale, n. 2, p. 451-508, 2007.

GARCÍA, G. A.; VIDAL, E. Q.; SERRANO, A. M. Mujer y conciencia fiscal. Crónica tributaria, n. 127, p. 9-26, 2008.

GIL, A. C. Métodos e técnicas de pesquisa social. 6o edição. São Paulo: Atlas. 2008.

HERNANDEZ, T.; MCGEE, R. W. Egyptian attitudes on accepting bribes. 2013. Disponível em SSRN: https://ssrn.com/abstract=2246212. Acesso em Janeiro de 2017.

HERNANDEZ, T.; MCGEE, R. W. Ethical attitudes toward taking a bribe: A study of three Latin American countries. 2014a.

HERNANDEZ, T.; MCGEE, R. W. Attitudes toward bribery in Australia: A demographic study. 2014b 
HUCK, H. M. Evasão e elisão: rotas nacionais e internacionais do planejamento tributário. São Paulo: Saraiva, 1997.

IBDF - International Bureau of Fiscal Documentation (2005). International Tax Glossary. 5th ed. The Netherlands, Barry Larking, 2005, p. 22, 101.

KASTLUNGER, B.; MÜEHLBACHER, S.; KIRCHLER, E.; MITTONE, L. What goes around comes around? Experimental evidence of the effect of rewards on tax compliance. Public Finance Review, v. 39, n. 1, p. 150-167, 2011.

KIRCHLER, E. The economic psychology of tax behaviour. Cambridge, UK: Cambridge University Press. 2007.

KIRCHLER, E.; MÜEHLBACHER, S.; KASTLUNGER, B.; WAHL, I. Why pay taxes? A review of tax compliance decisions. 2010. In: ALM, J.; MARTINEZ-VAZQUEZ, J.; TORGLER, B. (Eds.). Developing alternative frameworks for explaining tax compliance (p. 15-31). Abingdon, UK: Routledge. 2010.

KIRCHLER, E.; KOGLER, C.; MÜEHLBACHER, S. Cooperative tax compliance: from deterrence to deference. Current Directions in Psychological Science, v. 23, n. 2, p. 87-92.

KLEIN, A. A Ética como Justiça Tributária. Revista Eletrônica do Curso de Direito das Faculdades OPET, n. 8, p. 354-371, 2014.

LEVINER, S. An overview: a new era of tax enforcement - from "big stick" to responsive regulation. Regulation \& Governance, v. 2, p. 360-380, 2008.

MACIEL, E. Ética e Tributo Working paper. 2004. Disponível em: http://www.braudel. org.br/novo/eventos/conferencias/2004/art_maciel_05.pdf. Acessado em Dezembro de 2016.

MCGEE, R. W. Is It Unethical to Evade Taxes in an Evil or Corrupt State? A Look at Jewish, Christian, Muslim, Mormon and Baha'i Perspectives. Journal of Accounting,Ethics \& Public Policy, v. 2, n. 1, p. 149-181, 1999 a.

MCGEE, R. W. Why People Evade Taxes in Armenia: A Look at an Ethical Issue Based on a Summary of Interviews. Journal of Accounting, Ethics \& Public Policy, v. 2, n. 2, p. 408-416, 1999 b.

MCGEE, R. W.; LINGLE, C. The Ethics of Tax Evasion: A Survey of Guatemalan Opinion. Presented at the 60th International Atlantic Economic Conference, New York, October 6-9, 2005. 
MCGEE, R. W. The Ethics of Tax Evasion: A Survey of International Business Academics, Presented at the 60th International Atlantic Economic Conference, New York, October 6-9. 2005a.

MCGEE, R. W. The Ethics of Tax Evasion: A Survey of Romanian Business Students and Faculty. Andreas School of Business Working Paper Series, Barry University, Miami Shores, FL 33161, USA, September. 2005b.

MCGEE, Robert W.; NICKERSON, Inge. WHEN IS TAX EVASION ETHICALLY JUSTIFIABLE? A SURVEY OF GERMAN OPINION. Academy of Legal, Ethical and Regulatory Issues, p. 35, 2005.

MCGEE, R. W.; TYLER , M. Tax Evasion and Ethics: A Demographic Study of 33 Countries). Working Paper. 2006. Disponível em <SSRN:http://ssrn.com/ abstract $=940505>$. Acesso em Nov/2016.

MCGEE, R. W.; COHN, G. Jewish Perspectives on the Ethics of Tax Evasion. Andreas School of Business Working Paper, Barry University, September. 2006.

MCGEE, R. W. Marital status and the ethics of tax evasion. In: The ethics of tax evasion (p. 475-484). Springer New York. 2012.

MCGEE, R. W. Gender and the ethics of tax evasion: An empirical study of 82 countries. In The ethics of tax evasion (pp. 415-439). Springer New York. 2012b

MCGEE, R. W., PETRIDES, Y., ROSS, A. M. Ethics and tax evasion: a survey of Mexican opinion. In The Ethics of Tax Evasion (pp. 387-403). Springer New York. 2012.

MCGEE, R. W. The Ethics of Tax Evasion. Handbook of Research on Economic Growth and Technological Change in Latin America, 379. 2014.

MCGEE, R. W., ROSS, A. A Demographic Study of Polish Attitudes Toward Tax Evasion. 2014b

MCGEE, R. W. The panama papers: A discussion of some ethical issues. 2016

MÜEHLBACHER, S., KIRCHLER, E. Mental accounting of self-employed taxpayers: on the mental segregation of the net income and the tax due. FinanzArchiv: Public Finance Analysis, v. 69, n. 4, p. 412-438, 2013.

MÜEHLBACHER, S.; KIRCHLER, E.; SCHWARZENBERGER, H. Voluntary versus enforced tax compliance: empirical evidence for the "slippery slope" framework. Eur J Law Econ, v. 32, p. 89-97, 2011.

POHLMANN, M. C.; IUDÍCIBUS, S. Classificação da pesquisa tributária: uma abordagem interdisciplinar. Enfoque: reflexáo contábil, v. 25, n. 3, p. 57-71, 2006. 
QUARESMA, R. A. Ética, direito e cidadania: Brasil sociopolítico e jurídico atual. Curitiba: Editora Juruá. 2008.

SOUZA, M. V. S. G. Elisão e evasão fiscal. 2005. Boletim Jurídico, Uberaba/MG, a. 3, no 127. Disponível em: <http://www.boletimjuridico.com.br/>. Acesso em: Jan. 2017.

TIPKE, K. Moral tributária Del estado y de los contribuintes. Madrid: Marcial Pons, 2002.

TORGLER, B. Tax Compliance and Tax Morale: A Theoretical and Empirical Analysis. Cheltenham, UK: Edward Elgar, 2007.

TORGLER, B.; SCHAFFNER, M.; MACINTYRE, A. Tax compliance, tax morale, and governance quality. International Studies Program Working Paper, Andrew Young School of Policy Studies, Georgia State University. 2007.

TORGLER, B.; SCHNEIDER, F. Shadow Economy, Tax Morale, Governance and Institutional Quality: A Panel Analysis. 2007.

TORGLER, B.; DEMIR, I. C.; MACINTYRE, A.; SCHAFFNER, M. Causes and consequences of tax morale: An empirical investigation. Economic Analysis and Policy, v. 38, n. 2, p. 313-339, 2008.

TORGLER, B. Tax Morale and Compliance: Review of Evidence and Case Studies for Europe. World Bank Policy Research Working Paper No. 5922. 2011. Disponível em SSRN: https://ssrn.com/abstract=1977173. Acesso em: Jan. 2017.

VON NEUMANN, J; MORGENSTERN, O. Theory of games and economic behavior. Princeton University Press. 1944. 